Wilfrid Laurier University

Scholars Commons @ Laurier

\title{
The Role of Hardiness in Moderating the Relationship between Global/Specific Attributions and Actions against Discrimination
}

Mindi D. Foster

Wilfrid Laurier University, mfoster@wlu.ca

Kenneth L. Dion

University of Toronto

Follow this and additional works at: https://scholars.wlu.ca/psyc_faculty

Part of the Psychiatry and Psychology Commons, and the Social Psychology Commons

\section{Recommended Citation}

Foster, M.D. \& Dion, K.L. Sex Roles (2004) 51: 161. doi:10.1023/B:SERS.0000037760.64813.0b

This Article is brought to you for free and open access by the Psychology at Scholars Commons @ Laurier. It has been accepted for inclusion in Psychology Faculty Publications by an authorized administrator of Scholars Commons@ @aurier. For more information, please contact scholarscommons@wlu.ca. 


\title{
Running head: HARDINESS, ATTRIBUTIONS AND ACTION
}

The Role of Hardiness in Moderating the Relationship between Global/Specific Attributions and Actions against Discrimination.

Mindi D. Foster

\section{Wilfrid Laurier University}

\author{
Kenneth L. Dion
}

University of Toronto

\begin{abstract}
In this study, we proposed that individual differences in hardiness may moderate the relationship between global attributions and actions against discrimination. Specifically, global attributions were expected to predict decreased endorsement of actions to combat discrimination among low hardy women. In contrast, global attributions were expected to predict increased endorsement of actions among high hardy women. High and low hardy women were exposed to a laboratory situation of discrimination, and their attributions for, and responses to, discrimination were then assessed. Results showed the expected interaction, but in the opposite direction: among low hardy women, global attributions predicted stronger endorsement of action. Among high hardy women, specific attributions predicted stronger endorsement of action. Theoretical and practical implications are discussed.
\end{abstract}

Keywords: gender discrimination, hardiness, attributions, collective action.

The Role of Hardiness in Moderating the Relationship between Global/Specific Attributions and Actions against Discrimination If, upon experiencing discrimination, a woman makes a global attribution for that experience (i.e., the event can affect many contexts in life), common 
sense would suggest that this woman may reason as follows:"It's at home, at school, at work-it's everywhere--- I give up, I can't change anything, I might as well accept it." Indeed, learned helplessness research has shown that negative psychological and physical symptoms are increased and instrumental behaviors are decreased when global attributions are a part of one's cognitive style (Abramson, Metalsky, \& Alloy, 1989; Abramson, Seligman, \& Teasdale, 1978; Alloy, Peterson, Abramson, \& Seligman, 1984; Amirkhan, 1998 ; NolenHoeksema, Girgus, \& Seligman, 1986; Peterson \& Seligman, 1984, 1987; Seligman, 1975).

However, recent research has shown that in an intergroup context of discrimination, global attributions promote more positive instrumental behaviors against discrimination (Foster, 2000, 2001). In those studies, Foster $(2000,2001)$ suggested that previous learned helplessness research had focused on attributions for situations that are happening to an individual alone (e.g., getting sick or getting fired) rather than attributions for group-based discrimination, a situation that also affects the larger social group. It was further argued that alternative theories, namely theories of group consciousness (e.g., Bartky, 1977; Bowles \& Klein, 1983; Carey, 1980; Lerner, 1986) provide a framework for understanding global attributions for discrimination as facilitative versus debilitating. More specifically, group consciousness theories are historically based in grass roots movements such as consciousness-raising groups that sought to redefine women's attributions for discrimination (e.g., Bartky, 1977). In these groups, women came together to talk about everyday experiences, and in doing so, they heard about each others' experiences of domestic abuse; harassment from teachers, bosses, and on the streets from strangers; pay inequities and limited career opportunities; and other types of sexism. In hearing about the wide variety of contexts in which gender discrimination affected women, participants in these groups began to reinterpret what was previously thought to be an isolated incident into something that was affecting many aspects of their lives. For example, a woman who was being harassed by a male colleague at work may have 
initially reasoned that the cause of such treatment was isolated to this one person and would only occur at work. However, after hearing about the many types of inequities that were occurring in others' lives, she presumably came to view the cause of her treatment as able to affect many aspects of her life; sexism became apparent in many forms, across many contexts. In other words, women in consciousness-raising groups were encouraged to make global attributions for discrimination.

Further, these groups encouraged women to recognize that if the experience of the group could affect so many aspects of life, then ultimately, their lives would not be immune from the effects of discrimination (e.g., Bowles \& Klein, 1983). Global attributions were therefore presumed to make the experience of the group more personally relevant, as expressed in the slogan "personal as political" (e.g., Carey, 1980). In turn, if what happens to the group is personally relevant, then behaviors aimed at enhancing group status (i.e., collective action) would become more relevant to enhancing one's own status. Thus, unlike learned helplessness theories, group consciousness theories would suggest that global attributions for discrimination may be associated with instrumental behaviours such as actions to combat discrimination. Consistent with this, research has shown that the more women made global attributions for hypothetical scenarios of discrimination, the more they reported that women's general experiences of discrimination were relevant to them personally (Foster 2000, 2001), which, in turn, was related to enhanced participation in collective action (Foster, 2000). This relationship has also been replicated in a laboratory situation where women personally experienced an academic situation of gender discrimination (i.e., women received false feedback that they have failed an academic task, whereas men received false feedback that they passed). The more women made global attributions for this experience (i.e., rated it as being able to affect other contexts in their lives), the more they endorsed taking individual and collective actions (Foster, 2001). Thus, in an intergroup context of discrimination, global attributions may be an "a-ha" experience, which serves 
to facilitate, rather than to inhibit, corrective actions.

Although an "a-ha" experience can be motivational, group consciousness theories recognize that such experiences are also overwhelming, and often difficult to cope with (Weskott, 1983). In addition, Branscombe and colleagues (e.g., Branscombe, Schmitt \& Harvey, 1999) have shown that defining discrimination as pervasive across contexts can have negative consequences for psychological well-being. For example, the more women considered prejudice to occur across a variety of contexts, the more they reported depression, anxiety and decreased self-esteem (Branscombe, et al., 1999; Schmitt, Branscombe, Kobrynowicz, \& Owen, 2002). In an experimental study that tested the causal relationship between perceived pervasive discrimination and well-being, Schmitt, Branscombe, and Postmes (2003) manipulated situations of pervasive versus rare discrimination and found that those exposed to pervasive discrimination reported lower selfesteem and less positive affect than those exposed to rare discrimination. Taken together, these two lines of research suggest that for some, global attributions for discrimination may be a positive, motivational experience (Foster, 2001) or a negative psychological experience (Branscombe et al., 1999). An unanswered question, therefore, is what may predict who will cope positively with the recognition that discrimination is pervasive and who will become too overwhelmed to participate in collective action.

An important factor noted by Branscombe and colleagues (Branscombe et al., 1999; Schmitt et al., 2002) is group identification. Those who perceive discrimination as pervasive often respond by increasing their group identification. That is, one way to cope with the rejection from an outgroup is to increase one's connection with the outgroup. In turn, this serves to attenuate the negative effects of perceiving pervasive discrimination. Indeed, this model is consistent with group consciousness theories (Bartky, 1977); when global attributions make salient the connection between the individual and the group (Foster, 2001), group identification likely also increases. However, some individuals may not respond to rejection by the outgroup by 
heightening their identification with their group; there are individual differences in the degree to which people identify with their social groups (e.g., Mackie \& Smith, 2002). The variability among women's identification with their group may be especially noticeable, given the various ways in which women can define themselves as women, and even the desire to differentiate themselves from feminism (e.g., Russo, 1998; Williams \& Wittig, 1997). Thus, additional factors that predict who will cope well with perceived pervasive discrimination need to be investigated.

Stress and coping models (Lazarus \& Folkman, 1984) suggest that how individuals respond to potentially stressful events is a function of the interactive relationship between primary appraisals of the event (i.e.,"what is the nature of the problem?") and secondary appraisals (i.e., "what can I do about it?"). For some individuals, as Branscombe et al. (1999) have shown, appraising the nature of the problem as pervasive (i.e., "the problem of discrimination is widespread") may reduce well-being (i.e., increased depression and anxiety, reduced self-esteem). Further, learned helplessness theories would suggest that such negative symptoms would reduce taking instrumental actions (Abramson et al., 1978). At the same time however, if these individuals make secondary appraisals of the event in which they believe they have the resources to cope with discrimination, instrumental coping behaviors may increase. These individuals may define discrimination as pervasive, but also may view themselves as more resilient, and therefore, they may be more likely to take actions to combat discrimination.

One personality type thought to encompass the notion of resiliency is the Hardy individual. Hardiness is defined as “...provid[ing] the courage to confront change or adversity and turn it to advantage instead of being debilitated by it" (Maddi \& Khoshaba, 1994, p. 1). Those high in hardiness exhibit a sense of commitment to whatever they are involved in; they believe they have control over their lives; and they are challenged by negative experiences rather than debilitated by them (Maddi, 1987). There is empirical evidence that hardiness is associated with greater well-being and that increased 
well-being is achieved through the use of active coping responses (Allred \& Smith, 1989; Berwick, 1992; Maddi, 1987, 1999; Maddi \& Khoshaba, 1996; Maddi, Wadhwa, \& Haier, 1996; Nakano, 1990; Narsavage \& Weaver, 1994; Rhodewalt \& Agustsdottir, 1989; Rush, Schoael, \& Barnard, 1995). For example, the more hardy people are, the more they will use problem-focused coping (Wiebe, 1991; Williams, Wiebe, \& Smith, 1992) and health protective behaviors such as eating well and exercising regularly (Wiebe \& McCallum, 1986). Thus, hardiness is said to have positive effects on well-being via the use of more active coping mechanisms.

There is less research, however, on how hardiness may facilitate responses to discrimination. Studies that do exist suggest that hardiness also aids coping in intergroup contexts. Dion, Dion, and Pak (1992) found that members of Toronto's Chinese community who were low in hardiness showed a positive relationship between experienced discrimination and psychological symptoms, which suggests that the more they perceived themselves to be victims of discrimination, the more symptoms (e.g., sleep problems, nervousness) they experienced. However, Chinese-Canadians high in hardiness showed no relationship whatsoever between discrimination and stress symptoms. Foster and Dion (2003) found that compared to low hardy women, women who scored high in hardiness showed greater positive affect, higher self-esteem, and less anxiety after being exposed to both a hypothetical and a personal encounter with gender discrimination in a laboratory setting. These studies suggest that being hardy may provide people with a "buffer" against the illeffects of discrimination. However, whether hardiness may be related taking actions against discrimination, and, further, whether it may moderate the relationship between attributions and action, has not yet been tested.

Given the conceptual definition of hardiness as resilience, as well as the empirical evidence in intrapersonal contexts (e.g., Wiebe \& McCallum, 1986), we expected hardiness to be motivational. Specifically, high hardy women were expected to endorse more actions to combat discrimination than low hardy women. Further, the conceptualization of hardiness also suggests that 
high hardy women, as those who are not debilitated by adversity, may be more likely to overcome any negative consequences that may be associated with defining discrimination as global. Thus, it was expected that high hardy women who make global attributions for discrimination would endorse more action than would low hardy women who make global attributions. In contrast, given the low threat nature of specific attributions, it was expected that high and low hardy women who made specific attributions would not differ in their action-taking.

\section{Method}

\section{Participants}

Female introductory psychology students $(\underline{N}=391)$ at the University of North Dakota were first pre-screened for their level of dispositional hardiness using the Personal Views Survey III (Maddi \& Khoshaba, 1994). Participants were then considered for participation in the present study if they scored in the top one-third (high hardy) or bottom (low hardy) one-third of the distribution of hardiness scores. Of those that fell into the upper and lower thirds, 57 high and 57 low hardy women were telephoned and asked to participate in exchange for course credit. Participants' average age was 21.2 years and selfreported ethnicity of students was 93\% European-American, 2.2\% AmericanIndian, and $4.8 \%$ "other."

\section{Procedure}

Participants 1 entered the lab in groups of 5 to 10 and the female experimenter gave an overview of what the experiment would entail, which was, in reality, a cover story designed to conceal the purpose of the study. Specifically, participants were told that this was an experiment in a program of studies of test-taking anxiety. To assess how their anxiety might be related to test performance, they would first complete a task that often appears on standardized language placement tests. They would be given a list of 10 stimulus words to use as the basis for writing a paragraph that is creative, logical, and succinct, and then they would be given 5 minutes to write their 
paragraphs. After they completed their paragraphs, their scores would be assessed by the experimenter using the criteria that testing agencies had allegedly provided. Only the highest scoring participants would then be selected to enter what was called the "video group." The other participants would remain behind to participate in a second part of the experiment.

The purpose of these group delineations was to simulate an intergroup situation (Foster, 2001; Foster, Matheson, \& Poole, 1994; Wright, Taylor, \& Moghaddam, 1990). To reflect a hierarchical organizational context, the methodological goal was to establish a "dominant" group that participants would aspire to join because inclusion would reflect personal success and high social value. The second "subordinate" group would represent a relative lack of success and low social value. This differential evaluation of the two groups was achieved by varying the mundaneness of the task and the rewards associated with the work performed. Supposedly, those who performed well (i.e., the video group) would be asked to provide the experimenter with some ideas about how to develop a video for students that might help them to overcome the anxiety associated with test-taking. They were told they would do this in a different experimental room where refreshments would be served and that they would be eligible for a $\$ 100$ lottery. Thus, their skills were valued by the experimenter, and they could potentially receive a large reward.

In contrast, those who did not perform well would allegedly continue to complete a series of further tests that would assess whether their low performance generalized to other types of skills such as math. Also, they would only be eligible for a $\$ 10$ lottery. Thus, their continuation in the experiment would be tedious, their skills less valued by the experimenter, and only a small reward could potentially be received. In reality, the task and scoring were bogus, and all participants were eligible for the $\$ 100$ lottery.

After describing the different tasks, the experimenter made the potential for gender discrimination salient by stating:

I should warn you that this task and the way it is scored could be 
considered to be discriminatory against women. It seems that women don't do well on this task and so it is very rare that women are allowed into the video group, whereas men almost always get in. We can talk about this after the experiment if you like, but we do have time limitations for this experiment, so we should continue.

Participants were then given 5 minutes to write their paragraphs, which were then collected and ostensibly scored. After the scoring, false feedback was given such that only women received a failing score, whereas all men received a passing score. Those who passed were then asked to follow the experimenter to a different room where they would presumably participate in the video development. At this point it became clear to participants that consistent with the experimenter's previous warning, only men received the necessary passing score and left the room with the experimenter, allegedly to join the prestigious 'video' group , at which time the men were debriefed and dismissed.

After the men had left, the experimenter asked the female participants to complete a questionnaire and stated that the second part of the experiment would follow the questionnaire. This questionnaire was presumably designed to assess their opinions on the use of the task but actually contained the manipulation checks and measures of moderating and dependent variables. Once they had completed the questionnaire, they were told that this was the end of the experiment and then given both an oral and a written debriefing. The debriefing, which was given to both women and men, was a detailed, four-page description of the purpose of the study, an explanation as to why deception was necessary, repeated confirmation that their performance was not actually measured, as well as a contact sheet with phone numbers of local counseling centers, the researcher, and the chair of the Psychology Department. Discussions after debriefing indicated that participants understand the need for deception in order to obtain spontaneous reactions, and no adverse reactions have been reported (Foster, 1999, 2001; Foster, Matheson, \& Poole, 1994). 


\section{Materials}

Personal Views Survey III (PVS-III; Maddi \& Khoshaba, 1994). On a scale that ranged from "not at all true" (0) to "completely true" (3), participants indicated the extent to which each of 30 items reflected their current life situation. The PVS measures three constructs: committement ("I really look forward to my work"), perceived control ("What happens to me tomorrow depends on what I do today") and a positive view of challenging events ("It is exciting to learn something new about myself.") A sum score of the items was used. The measures were scored by the Hardiness Institute $(\underline{M}=60, \underline{S D}=$ 6.52). Those in the top (cutoff $=64$ ) and bottom (cutoff $=56$ ) thirds of the distribution were classified as high and low hardy respectively. Cronbach alpha was .84.

Manipulation check. To assess whether an experience of gender discrimination was adequately portrayed, participants responded to the question "Ethical guidelines require that we ask how fairly was your gender treated in the present experiment?" on a scale that ranged from "not at all" (0) to "extremely" (10).

Attributions. Participants read the following: "Today in the experiment you were told that you either passed or failed a certain task. Does the reason you either passed or failed the task influence just this situation, or does it also influence other areas of your life?" This question was based on the Attribution Style Questionnaire (ASQ; Peterson, et al., 1982) and was scored on a 0 to 10 scale such that lower scores indicated specific attributions and higher scores indicated global attributions.

Actions against discrimination . Based on Wright, Taylor, and Moghaddam's (1990) classification of actions, we asked participants to indicate the extent to which they would participate in each of five behaviors given the opportunity to respond to their treatment in the present experiment. Items were rated on a scale that ranged from "extremely unlikely to participate" (0) to "extremely likely to participate" (10). Two items reflected 
individual behaviors, that is, behaviour aimed at enhancing individual status ("Request an individual retest of your score"; "Confront the experimenter and demand an explanation of your particular group assignment"). The mean of these two items was used as the overall individual action score, $r=.54, p=$ .01. Two items reflected collective behaviors, that is, behaviors aimed at enhancing group status ("Ask that the group be retested on their scores"; "Get together with other students to confront the experimenter, demanding an explanation for your group assignment"). The mean of these two items was used as the overall collective action score, $r=.55, p=.01$. One item reflected an acceptance of discrimination ( " accept the situation, that is, your assignment to either group, as is").

\section{Results}

\section{Manipulation Check}

In order for the manipulation of discrimination to have been successful, participants should have scored on the low end of the scale, an indication of perceived gender unfairness. Testing each group's perceived gender unfairness against the midpoint of the scale (5), a one-sample t -test showed that the means for both the low $(M=2.98, S D=3.01), t(56)=-5.06, p=$ .0001 , and high hardy groups $(M=3.02, S D=3.07), t(56)=-4.87, p=.0001$, were significantly lower than the midpoint. Further, it was desirable for both low and high hardiness groups to perceive the same degree of unfairness so that the level of perceived discrimination would not be a confound. A twosample $\mathrm{t}$-test indicated that both high and low hardy groups of women perceived their gender to have been unfairly treated, $\underline{t}(112)=-.062$, ns. Thus, the manipulation of gender discrimination was successful.

\section{Main Analysis}

Based on Aiken and West's (1991) method of testing interactions between categorical (hardiness) and continuous (attribution) variables, a hierarchical regression was conducted for each of the dependent variables (individual, collective actions and acceptance). Hardiness, which was dummy coded, and 
the attribution measure (which was first centered) were entered on the first step. The multiplicative interaction (between hardiness and the centered attribution variable) was then entered on the second step. Zero-order correlations are reported in Table 1.

Although the main effects did not significantly predict individual actions, $F$ $(2,111)=.074, p=.929$, the interaction between hardiness and attributions explained $8.6 \%$ of the variability in individual action, $F(1,110)=10.42, \beta=$ -.413. $p=.002$, The interaction was plotted (see Figure 1), and simple effects analysis showed that the more high hardy women made global attributions for their experience, the less individual action they endorsed, $t(55)=-2.60, p=$ .012. For low hardy women, there was a near significant relationship between attributions and action such that the more they made global attributions, the more individual action they endorsed, $\mathrm{t}(55)=1.96, \mathrm{p}=.055$.

Again, the main effects did not significantly predict collective actions, $F$ $(2,111)=.176, p=.839$. However, the interaction between hardiness and attributions explained $7.1 \%$ of the variability in collective action, $F(1,110)=$ $8.42, \beta=-.374, p=.004$. The interaction was plotted (see Figure 2), and simple effects analysis showed that the more high hardy women made global attributions, the less collective action they endorsed, $\mathrm{t}(55)=-2.30, p=.025$.

The relationship between attributions and action was marginally significant for low hardy women, such that the more low hardy women made global attributions, the more collective action they endorsed, $t(55)=1.75, p=.086$.

Neither the main effects, $\mathrm{F}(2,111)=.300, p=.741$ nor the interaction significantly predicted acceptance of discrimination, $F(1,110)=.163 p=.465$.

\section{Discussion}

The goal of the present study was to examine whether hardiness would be related to actions to combat discrimination and whether it might moderate the relationship between attributions and actions against discrimination. There was no main effect for hardiness, which suggests that, on its own, hardiness did not predict endorsing actions to combat discrimination. Instead, as 
expected, there was an interaction between hardiness and attributions, which suggests that, consistent with stress and coping theories (Lazarus \& Folkman, 1984), primary (attributions for the event) and secondary (perceived resources) appraisals interacted to predict responses to a stressful situation. However, the direction of relationships was unexpected: it was low hardy women for whom global attributions appeared to facilitate action-taking. Although this finding should be interpreted with caution given its marginal significance, it is possible that for low hardy women who report having fewer personal resources than high hardy women, global attributions may provide the extra resources needed to encourage their action-taking. Group consciousness theories suggest that global attributions for discrimination may increase the perception that social resources are available (e.g., Bartky, 1977). For example, the more women recognized that discrimination is global across contexts, the more they recognized that the group experience is also shared by them personally (Foster, 2000, 2001). Thus, global attributions may provide low hardy women with the necessary perceived social support that may motivate their action-taking.

In contrast, high hardy women who made specific attributions endorsed more individual and collective actions to combat discrimination than they did if they made global attributions. Thus, for high hardy women, defining discrimination as isolated rather than global, was more motivational. This finding is inconsistent with group consciousness theories of collective behavior (e.g., Bartky, 1977), which suggest that the less pervasive discrimination is perceived to be, the less likely disadvantaged group members are to perceive the need for actions to combat it. In support of this, research has shown that the more women define discrimination as isolated, the less likely they are to take collective actions aimed at increasing group status (Foster, 2001). Thus, hardy women seem to endorse actions to combat discrimination, despite having defined discrimination as isolated. One possible explanation is that patterns of appraisals may differ depending on what is being appraised: the situation of discrimination, or the behavioral response to discrimination. In particular, hardy women who appraised discrimination as 
isolated may have nevertheless appraised the potential behavioral responses as positively challenging, an appraisal consistent with the conceptual definition of hardiness. Thus, despite defining discrimination as isolated, hardy women may still be motivated to take actions to combat discrimination.

If hardy women are using specific attributions to define discrimination, but nevertheless believe discrimination requires widespread corrective action, then hardiness may facilitate an desirable set of appraisals. Specifically, as we have shown in past work (Foster \& Dion, 2003), the well-being of hardy women is achieved through attributions; the relationship between hardiness and increased self-esteem and decreased anxiety was mediated through specific attributions for discrimination. Thus, defining a situation of discrimination as isolated may serve to reduce the threat, thereby protecting psychological wellbeing. At the same time, high challenge appraisals of subsequent behaviours may serve to motivate action-taking, thereby protecting collective well-being. Such a combination of appraisals therefore may be most desirable for women who are facing discrimination. In future research we will examine how appraisals of discrimination and behavioral responses may vary and how such differences may reflect well-being. For example, videotaped scenarios of discrimination versus scenarios of behavioral responses to discrimination may be used to ascertain the different patterns of appraisals that hardy women may make about the experience of, and the behavioral responses to discrimination.

Future research will also need to examine a more expanded operational definition of perceived pervasiveness. To remain consistent with learned helplessness theory global attributions were defined as the belief that the cause of an event is pervasive across contexts (e.g., Abramson et al., 1978) . In addition, the one-item measure was derived from the Attributional Style Questionnaire (Peterson et al., 1982) . However, there are likely several aspects of pervasiveness that have different implications for well-being. For example, recent research shows that when women are reading about discrimination happening to someone else, they define it as long-term, but women envisioning discrimination happening to themself are less likely to 
define it as long-term (Foster, Jackson, Hartmann \& Woulfe, in press). Thus, acknowledging that discrimination is pervasive across time may be more threatening to well-being than perceived pervasiveness across context. Similarly, "frequency" of discrimination may have different implications than discrimination across contexts; a woman may see a discriminatory event as frequently occurring (e.g., sexist remarks) but not necessarily believe that this event will affect other situations of her life. In future research, we will examine the different types of pervasiveness, and their implications for wellbeing and behavior.

Also in need of investigation is the long-term implications of definitions of discrimination. If hardy women continue to define discrimination as isolated, the long-term consequences may not be positive. Some evidence suggests that the use of specific attributions to define discrimination may be an avoidant strategy for coping with discrimination. For example, when presented with higher threat discrimination conditions (i.e., exposure to personal discrimination scenarios), high hardy women defined discrimination as isolated. In contrast, when exposed to lower threat conditions of discrimination (i.e., scenarios that depicted others' experience of discrimination), high hardy women defined discrimination as global (see Study 3, Foster \& Dion, 2003). Thus, when discrimination was less likely to affect them personally, high hardy women defined the discrimination as pervasive across contexts. However, when the threat of discrimination became personally relevant, high hardy women minimized the pervasiveness. Thus, for high hardy women, global attributions for personal discrimination may be a threatening experience. Defining discrimination as isolated may be a threatreducing tool that enables them to act when they personally experience discrimination. Such a tool, however, may not be a positive strategy in the long run . Pennebaker and colleagues (e.g., Pennebaker, 1993; Pennebaker \& Keough, 1999; Pennebaker \& Susman, 1988) have shown that avoidance strategies may have long- term health risks. Thus, future researchers will also need to examine the coping processes of hardy women over time. It may be 
that the strategies used by hardy women are effective in the short-term, but may be harmful in the long-term.

\section{References}

Abramson, L. Y., Metalsky, G. I., \& Alloy, L. B. (1989). Hopelessness depression: A theory-based subtype of depression. Psychological Review, $96,358-372$.

Abramson, L. Y., Seligman, M. E. P., \& Teasdale, J. (1978). Learned helplessness in humans: Critique and reformulation. Journal of Abnormal Psychology, 87, 49-74.

Aiken, L. S., \& West, S. G. (1991). Multiple regression: Testing and interpreting interactions. Thousand Oaks, CA: Sage.

Allred, K. D., \& Smith, T. W. (1989). The hardy personality: Cognitive and physiological responses to evaluative threat. Journal of Personality and Social Psychology, 56, 257-266.

Alloy, L. B., Peterson, C., Abramson, L. Y., \& Seligman, M. E. P. (1984). Attributional style and the generality of learned helplessness. Journal of Personality and Social Psychology, 46, 681-687.

Amirkhan, J. H. (1998). Attributions as predictors of coping and distress. Personality and Social Psychology Bulletin, 24 , 1006-1018.

Bartky, S. L. (1977) Toward a phenomenology of feminist consciousness. In M. Vetterling-Braggin, F. Elliston, \& J. English (Eds.), Feminism and philosophy (pp. 22-37). Totowa, NJ: Littlefield.

Berwick, K. R. (1992). Stress among student affairs administrators: The relationship of personal characteristics and organizational variables to workrelated stress. Journal of College Student Development, 33 , 11-19.

Bowles, G., \& Klein, R. D. (1983). Theories of women's studies . London: Routledge.

Branscombe, N. R., Schmitt, M. T., \& Harvey, R. D. (1999). Perceiving 
pervasive discrimination among African-Americans: Implications for group identification and well-being. Journal of Personality and Social Psychology, 77, 135-149.

Carey, P. (1980). Personal is political. Canadian Women's Studies , 2, 4-7.

Dion, K. L., Dion, K. K., \& Pak, A. W-p. (1992). Personality-based hardiness as a buffer for discrimination-related stress in members of Toronto's Chinese community. Canadian Journal of Behavioural Science, 24 , 517-536.

Foster, M. D. (1999). Acting out against discrimination: The effects of different social identities. Sex Roles, 40, 167-186.

Foster, M. D. (2000). Utilization of global attributions in recognizing and responding to gender discrimination among college women. Current Psychology, 19, 57-69.

Foster, M. D. (2001). The motivational quality of global attributions in hypothetical and experienced situations of gender discrimination. Psychology of Women Quarterly, 25, 242-253.

Foster, M. D., \& Dion, K. L. (2003). Dispositional hardiness and women's well-being relating to gender discrimination: The role of minimization. Psychology of Women Quarterly, 27, 197-208.

Foster, M. D., Matheson, K., \& Poole, M. (1994). Responding to sexual discrimination: The effects of societal versus self-blame. Journal of Social Psychology, $134,743-754$.

Foster, M. D., Jackson, C. L., Hartmann, R., \& Woulfe, S. (in press). Minimizing the pervasiveness of women's personal experiences of gender discrimination. Psychology of Women Quarterly .

Lazarus, R. S., \& Folkman, S. (1984). Stress, appraisal, and coping . New York: Springer.

Lerner, G. (1986). The creation of patriarchy. New York: Oxford University Press. 
Mackie, D. M., \& Smith, E. R. (2002). From prejudice to intergroup emotions: Differentiated reactions to social groups . New York: Psychology Press.

Maddi, S. R. (1987). Personal Values Survey II : A measure of dispositional hardiness. In C. P. Zalaquett \& R. J. Wood (Eds.), Evaluating stress: A book of resources. Lanham, MD: Scarecrow Press, Ltd.

Maddi, S. (1999). The personality construct of hardiness: I. Effects on experiencing, coping and strain. Consulting Psychology Journal, 51, 8394.

Maddi, S. R., \& Khoshaba, D. M. (1994). Personal Views Survey III . Newport Beach, CA: Hardiness Institute.

Maddi, S. R., \& Khoshaba, D. M. (1996). Hardiness and mental health. Journal of Personality Assessment, 63 , 265-274.

Maddi, S. R., Wadhwa, P., \& Haier, R. J. (1996). Relationship of hardiness to alcohol and drug use in adolescents. American Journal of Drug and Alcohol Abuse, 22, 247-257.

Nakano, K. (1990). Hardiness, Type A behavior, and physical symptoms in a Japanese sample. Journal of Nervous \& Mental Disease, 178, 52-56

Narsavage, G. L., \& Weaver, T. E. (1994). Physiologic status, coping, and hardiness as predictors of outcomes in chronic obstructive pulmonary disease. Nursing Research, 43 , 90-94.

Nolen-Hoeksema, S., Girgus, J. S., \& Seligman, M. E. P. (1986). Learned helplessness in children: A longitudinal study of depression, achievement, and explanatory style. Journal of Personality and Social Psychology, 51, $435-442$.

Pennebaker, J. W. (1993). Putting stress into words: Health, linguistic and therapeutic implications. Behavior Research and Therapy, 31 , 539-548.

Pennebaker, J. W., \& Keough, K. A. (1999). Revealing, organizing, and 
reorganizing the self in response to stress and emotion. In R. J. Contrada \& R. D. Ashmore (Eds.), Self, social identity, and physical health:

Interdisciplinary explorations . (pp. 101-121). New York: Oxford University Press .

Pennebaker, J. W., \& Susman, J. R. (1988). Disclosure of traumas and psychosomatic processes. Social Science \& Medicine, 26 [Special Issue: Stress and coping in relation to health and disease] , 327-332.

Peterson, C., \& Seligman, M. E. P. (1984). Causal explanations as a risk factor for depression: Theory and evidence. Psychological Review, 91 , 347-374.

Peterson, C. \& Seligman, M. E. P. (1987). Explanatory style and illness. Journal of Personality, 55 , 237-265.

Peterson, C., Semmel, A., von Baeyer, C., Abramson, L. Y., Metalsky, G.I., \& Seligman, M. E. P. (1982). The attributional style questionnaire. Cognitive Therapy and Research, 6, 287-299.

Rhodewalt, F., \& Agustsdottir, S. (1989). On the relationship of hardiness to the Type A behavior pattern: Perception of life events versus coping with life events. Journal of Research in Personality, 18, 211-223.

Rush, M. C., Schoael, W. A., \& Barnard, S. M. (1995). Psychological resiliency in the public sector: "Hardiness" and pressure for change. Journal of Vocational Behavior, 46 , 17-39.

Russo, N. F. (1998). Measuring feminist attitudes: Just what does it mean to be a feminist? Psychology of Women Quarterly, 22 , 313-316.

Schmitt, M. T., Branscombe, N. R., Kobrynowicz, D., \& Owen, S. (2002).

Perceiving discrimination against one's gender group has different implications for well-being in women and men. Personality and Social Psychology Bulletin, 28, 197-210.

Schmitt, M. T., Branscombe, N. R., \& Postmes, T. (2003). Women’s 
emotional responses to the pervasiveness of gender discrimination.

European Journal of Social Psychology, 33, 1-12 .

Seligman, M. E. P. (1975). Helplessness: On depression, development and death. San Francisco: Freeman

Westkott, M. (1983). Women's studies as a strategy for change: Between criticism and vision. In G. Bowles \& R. D. Klein (Eds.), Theories of women's studies . London: Routledge.

Wiebe, D. J. (1991). Hardiness and stress moderation: A test of proposed mechanisms. Journal of Personality and Social Psychology, 60, 89-99.

Wiebe, D. J., \& McCallum, D. M. (1986). Health practices and hardiness as mediators in the stress-illness relationship. Health Psychology, 5 , 425-438.

Williams, P. G., Wiebe, D. J., \& Smith, T. W. (1992). Coping processes as mediators of the relationship between hardiness and health. Journal of Behavioral Medicine , 15 , 237-255.

Williams, R. \& Wittig, M. A. (1997). “I'm not a feminist but...”: Factors contributing to the discrepancy between pro-feminist orientation and feminist identity. Sex Roles, 37, 885-904.

Wright, S. C., Taylor, D. M., \& Moghaddam, F. M. (1990). Responding to membership in a disadvantaged group: From acceptance to collective protest. Journal of Personality and Social Psychology, 58 , 994-1003.

\section{Author Note}

Correspondence may be directed to Mindi Foster, Dept. of Psychology, Wilfrid Laurier University, Waterloo, Ontario, N2L 3C5., Canada. Email: mfoster@wlu.ca. Data were collected while the first author was at the University of North Dakota.

This research was facilitated by a Social Sciences and Humanities Research Council Grant to the second author.

Portions of this research were presented at the meeting of the Society for the 
Psychological Study of Social Issues, Toronto, Canada , June, 2002.

\section{Footnote}

1. Men were also included in the experiment because past research has shown that the discrimination manipulation is more realistic when men are present (Foster, 2001; Foster, Matheson, \& Poole, 1994). However, because the men left the experiment before the dependent measures were collected, they were not included in the analysis.

Table 1

Intercorrelations among hardiness, attributions and actions .

$\begin{array}{lllll}1 & 2 & 3 & 4 & 5\end{array}$

1. Hardiness

2. Attributions $\quad-.25^{* *} \quad--$

3. Individual Action $\quad-.02 \quad-.03 \quad--$

4. Collective Action $\quad \begin{array}{lllll}.05 & -.06 & .71 * * & --\end{array}$

$\begin{array}{llllll}\text { 5. Acceptance } & .03 & -.07 & -.34 * * & -.33^{* *} & -\end{array}$

Note: $* *$ refers to $p<.01$

Figure Captions

Figure I: Individual action as a function of hardiness and attributions

Figure II : Collective action as a function of hardiness and attributions 
$\mathrm{Y}^{\prime}=.164 \mathrm{X}+.859$

$\mathrm{Y}^{\prime}=-.221 \mathrm{X}+1.78$

$\mathrm{Y}^{\prime}=.163 \mathrm{X}+.958$

$\mathrm{Y}^{\prime}=-.267+2.024$ 